\title{
Estimating brown hyaena occupancy using baited camera traps
}

\author{
Michelle Thorn ${ }^{1 *}$, Dawn M. Scott ${ }^{1}$, Matthew Green ${ }^{2}$ \\ Philip W. Bateman² \& Elissa Z. Cameron ${ }^{2}$ \\ ${ }^{1}$ University of Brighton, Biology Division, Cockcroft Building, Lewes Road, Moulsecoomb, Brighton, BN2 4GJ, U.K. \\ ${ }^{2}$ Mammal Research Institute, Department of Zoology and Entomology, University of Pretoria, \\ Pretoria, 0002 South Africa. \\ Received 26 November 2008. Accepted 24 April 2009
}

\begin{abstract}
Conservation and management of brown hyaenas (Hyaena brunnea) is hampered by a lack of information on abundance and distribution, which is difficult and labour-intensive to obtain. However, occupancy surveys offer a potentially efficient and robust means of assessing brown hyaena populations. We evaluate the efficacy of camera trapping for estimating brown hyaena occupancy, and the effect of environmental variables and lures on detection probability. We estimated population density in Pilanesberg National Park, South Africa, at $2.8 / 100 \mathrm{~km}^{2}$, occupancy at 1.0 and model-averaged detection probability at 0.1 . Using a fish lure increased detection probability to $\mathbf{0 . 2}$ and significantly increased encounter rates. We also found that brown hyaenas are more likely to be detected in areas of scrub or woodland rather than grassland. Our results suggest that 13 camera sites would be needed to achieve an occupancy estimate with S.E. of 0.05 , and a minimum of 16-34 sampling occasions (with and without the fish lure) should be used in comparable study areas. We conclude that camera trapping is a viable method of estimating brown hyaena occupancy at local and landscape scales and capture-recapture analysis is also possible at a local scale.
\end{abstract}

Key words: Africa, camera, carnivore, detection probability, hyaena, lure, occupancy.

\section{INTRODUCTION}

Brown hyaenas (Hyaena brunnea) occur throughout the southwest arid zone of Africa and are classified as near threatened (Wiesel et al. 2008). The species is suspected to be in population decline, mainly due to human persecution and habitat fragmentation (Mills \& Hofer 1998; Wiesel et al. 2008). Like many other African carnivores, conservation and management of brown hyaenas is hampered by a lack of accurate distribution and abundance data (Wiesel et al. 2008). Such information is difficult to obtain because the species is nocturnal, wide-ranging and occurs at low density (Mills \& Hofer 1998). However, camera trapping could be useful for estimating brown hyaena occupancy, which is defined as the overall proportion of an area that is occupied by a given species. Camera trapping has been successfully used in numerous carnivore studies world-wide, addressing topics such as species inventory, abundance, distribution, population structure, habitat use and behaviour (Cutler \& Swann 1999; Wilson \& Delahay 2001). However, the method has rarely been used in studies of the larger African carnivores

\footnotetext{
*To whom correspondence should be addressed.
}

E-mail: thorngreen@hotmail.com
(Marnewick et al. 2006; Kauffman et al. 2007; Marnewick et al. 2008) and never for surveying brown hyaenas. To date, Linkie et al. (2007) and MacKenzie et al. (2005) are the only published studies using camera trapping data to estimate occupancy.

Occupancy is calculated from presence/absence records and recent methodological advances have focused on producing estimates that are robust to 'false absences' and spatial or temporal variations in detection probability (MacKenzie et al. 2006). In addition, newly developed software (Hines 2006) enables non-statisticians to perform the modelling techniques that produce robust estimators (MacKenzie et al. 2006). As occupancy surveys require lower sample sizes than abundance surveys and are therefore less expensive (Zielinski 1997; MacKenzie et al. 2006), these developments have made occupancy estimates more accessible (MacKenzie et al.2006). Occupancy data can now be used to make robust inferences about numerous variables such as distribution, population size, resource selection, metapopulation dynamics and species interactions (MacKenzie et al.2006). Such estimates are useful for adaptive management of carnivore populations at local and landscape 
scales. However, optimal allocation of effort requires some idea of the likely occupancy and detection probability of the focal species (MacKenzie \& Royle 2005). Detection probability is defined as the probability of detecting at least one individual of a species during one sampling occasion, given that the species is present in the sampling area (Karanth \& Nichols 2002; MacKenzie et al. 2006)

Brown hyaenas occur at low densities (Mills \& Mills 1982; Skinner et al. 1995; Maude 2005), so the likelihood of an animal passing a camera trap is correspondingly low. Detection probability can be improved by increasing the density of traps in the sampling area (Karanth \& Nichols 2002). However, if limited cameras are available, higher trap density reduces the area that can be surveyed. Placing cameras in places frequented by focal species can also increase detection probability (Karanth \& Nichols 2002), but this requires knowledge of survey sites that is not always available in advance. Alternatively, baits or lures can be used to attract animals to camera traps. However, baiting can be time-consuming and costly and must therefore considerably increase detection probability to be useful. Baits and lures have been widely used in carnivore ecological studies (e.g. Mace et al. 1994; Zielinski 1995; McDaniel et al. 2000; Noyce et al. 2001; Howard et al. 2002), but to date the efficacy of lures as attractants for African carnivores has not been assessed.

Here we present an evaluation of camera trapping as a method of estimating brown hyaena occupancy in an area where they occur at high relative density. Our aim was to produce the initial estimates of occupancy and detection probability that are essential for efficient design of future surveys. We also investigated the effect of environmental variables and lures on detection probability in an effort to enhance the efficacy of the technique for our focal species.

\section{METHODS}

\section{Study area}

Our study was conducted at Pilanesberg National Park in the North West Province of South Africa ( $25^{\circ} 08^{\prime}$ to $25^{\circ} 22^{\prime} \mathrm{S}$; $26^{\circ} 57^{\prime}$ to $\left.27^{\circ} 13^{\prime} \mathrm{E}\right)$. The park spans $550 \mathrm{~km}^{2}$ of mixed Acacia and broadleaf bushveld habitat and is home to numerous mammalian carnivore species, including brown hyaena. Set in an extinct volcano, the park is bounded by three concentric rings of hills, with a flatter central basin. It is surrounded by an electrified predator-proof fence.

\section{Camera trapping}

We placed six passive infrared camera traps 2.4-3.7 km apart (= 1 camera $\left./ 9 \mathrm{~km}^{2}\right)$ in a $36 \mathrm{~km}^{2}$ area chosen for its accessibility to roads and relatively homogeneous habitat. We used two Deer Cam DC300 (Non Typical Inc., Park Falls, WI, U.S.A.; http://www.deercam.com) and four Camtrakker TM (CamTrakker, Watkinsville, GA, U.S.A.; http://www.Camtrakker.com) 35 mm camera units. To maximize detection probability, we selected camera trap sites near brown hyaena sign (tracks and scats; Karanth \& Nichols 2002; MacKenzie et al.2006). We attached them to trees at a height of $45 \mathrm{~cm}$ (approximately shoulder height for a brown hyaena; Karanth \& Nichols 2002). We used a delay of five minutes between consecutive photographs and set cameras for 24-hour operation because although brown hyaenas are nocturnal (Mills \& Hofer 1998) they are regularly sighted in Pilanesberg during daylight (M. Thorn, pers. obs.). We used standard sensitivity for Deer Cams and set all cameras to imprint time and date on photographs. The models used in data analysis assume no changes in occupancy during the study period (MacKenzie et al. 2006). Survey duration was therefore limited to 12 weeks to minimize the likelihood of such changes.

\section{Lure selection}

We conducted a preliminary experiment in July 2007 at Predator World Zoo, which is located approximately $5 \mathrm{~km}$ from the boundary of Pilanesberg National Park $\left(25^{\circ} 35^{\prime} \mathrm{S}, 27^{\circ} 16^{\prime} \mathrm{E}\right)$. The purpose of the experiment was to eliminate ineffective lures and identify two food and two scent lures that were most likely to attract brown hyaenas during camera trapping. However, Predator World has only one brown hyaena, so we widened the scope of the captive trials and tested several carnivore species to achieve a sample size that would produce meaningful results. We presented one side-striped jackal (Canis adustus), one brown hyaena, three caracals (Caracal caracal), two servals (Leptailurus serval) and one cheetah (Acinonyx jubatus) with cafeteria-style choices of cow (Bos primigenius taurus) offal, tinned pet food, tinned fish (salmon, Salmonidae), fruit, and a control lure (collectively termed food lures). We also offered fermented chicken (Gallus gallus) eggs, cat nip, cod (Gadus spp.) liver oil, cow blood, Calvin Klein's Obsession aftershave, and a control lure (scent lures). We chose these lures because they either approximated food items found in dietary 
analyses of relevant species (Mills \& Mills 1978; Owens \& Owens 1978; Smithers 1978; Grobler 1981; Rowe-Rowe 1982; Nowell \& Jackson 1996) or have performed well as baits or lures in other carnivore studies (Zielinski 1995; Andelt \& Wooley 1996; Bradshaw et al. 2000; McDaniel et al. 2000; Wilson \& Delahay 2001; Moruzzi et al. 2002; Mickleburgh \& Fisher 2003). They also have the advantage of being relatively inexpensive and easily obtained.

\section{Use of lures in camera trapping}

As heavy rain might impact lure effectiveness, we conducted the survey from 10 September to 2 December 2007, avoiding peak rainfall (de Villiers \& Mangold 2002). We used the four lures identified from the captive trials and a control lure (a rock without a lure) during the camera trapping experiment. We deployed lures in random order at each camera location, using all lures once at each location. We left each lure in place for seven days, after which they were removed. The cameras then remained unbaited for seven days prior to application of the next lure. These unbaited intervals were intended to ensure that responses to different lures could be considered temporally independent. To check this assumption, we carried out a simple linear regression of the results from consecutive unbaited periods using time (weeks) as the predictor variable and brown hyaena encounter rate as the response variable. A temporal trend in the results would indicate non-independence. Data from unbaited periods were used to ensure that trap response was not confounded with lure response. We assumed camera locations to be independent as species detection probability at each site was unlikely to be biased by the presence of other nonintrusive camera traps (Linkie et al. 2007). We also separated camera locations by $2.4-3.7 \mathrm{~km}$ to ensure that responses to each lure were unlikely to be biased by proximity to other lures.

Lures were placed approximately $2 \mathrm{~m}$ in front of the camera trap on a small rock. At the end of each baited period, we removed all rocks to ensure that no trace of the lure remained. We used control lures to ensure that responses were not due to the presence of a novel object. During unbaited periods we checked the camera traps once a week and replaced batteries and film as necessary. Food lures were consumed, so we replaced them daily to ensure that their effect was consistent throughout sampling. However it was unnecessary to renew scent lures every day as the smell was detectable for several days. Accordingly, we renewed scent lures every 3-4 days except after heavy rain, when we refreshed the lure the following day.

\section{Modelling occupancy}

Consecutive photographs of brown hyaenas were considered independent if they showed different individuals. When individuals could not be differentiated, consecutive photographs were considered independent if taken $\geq 30$ minutes apart (O'Brien et al. 2003). From the independent photographs, we calculated pooled brown hyaena encounter rates (number of independent photographs/trap days) for the period when each lure was deployed and separately for each unbaited period.

Next, we created a brown hyaena detection history for baited periods at each camera location, consisting of binary values with ' 1 ' indicating species detection during the sampling occasion and '0' indicating non-detection (Otis et al. 1978). Each 24-hour period was considered a single sampling occasion with a maximum of 35 baited sampling occasions per camera site. As we considered each camera location an independent site, each sampling occasion was a temporal repeat of the survey (Linkie et al. 2007).

We analysed the detection history in PRESENCE 2 (Proteus Wildlife Research Consultants, Dunedin, New Zealand; http://www.proteus.co.nz) to generate maximum likelihood estimates for detection probability $(p)$ and occupancy $(\Psi)$. For the purposes of this analysis, $\hat{p}$ represents the estimated detection probability for a single sampling occasion and $\hat{\psi}$ represents the estimated probability that the study area was occupied by at least one brown hyaena during the study period. However, $\hat{\psi}$ can also be interpreted as the overall proportion of a study area that is used by a given species and this definition is designated PAU (Proportion of Area Used; MacKenzie et al. 2006). PRESENCE 2 calculates parameter estimates from detection histories $(H)$ such as $\left(H_{i}\right)=0101$, which indicates that the species was detected on the second and fourth sampling occasion only. PRESENCE 2 then derives maximum likelihood parameter estimates from the appropriate probability statement. For example, the probability statement for $H_{i}$ would be $\operatorname{Pr}\left(H_{i}=0101\right)=\Psi\left(1-p_{1}\right) p_{2}\left(1-p_{3}\right) p_{4}$.

\section{Modelling covariates and lure effects}

We also used PRESENCE 2 to analyse the 
effect of temporal and spatial variables using the logit link function. We included lures in covariate analysis to minimize un-modelled sources of heterogeneity in $\hat{p}$ (MacKenzie et al. 2006). We analysed lures, mean daily temperature $\left({ }^{\circ} \mathrm{C}\right)$, daily rainfall $(\mathrm{mm})$ and prey abundance as survey-specific (i.e. time variant) covariates.

Prey availability for brown hyaenas is difficult to quantify, but live prey abundance is thought to be influential (Mills \& Mills 1978). O'Brien et al. (2003) found that photographic encounter rates correlated strongly with independent estimates of prey densities. We therefore used encounter rates to approximate and model the effect of prey abundance. We grouped independent photographs of prey species into small, medium or large size classes according to mean adult body weight using the same independence criteria as for brown hyaenas. We then produced a pooled encounter rate for each size class. We analysed habitat (grassland or scrub), elevation $(m)$, distance to disturbance sites $(\mathrm{m})$, distance to water $(\mathrm{m})$ and distance from roads $(m)$ as both site- and surveyspecific covariates. 'Disturbance sites' refers to places where tourists congregate, like hides and picnic sites, and areas frequented by park staff. We extracted values for site and survey covariates from GIS layers in ArcView v. 3.3 (ESRI Inc., Redlands, CA). The GIS layers were supplied by the North West Parks and Tourism Board and temperature and rainfall data were supplied by the South African Weather Service.

There were 11 potential covariates for $\hat{p}$ which would have lead to an unrealistic number of candidate models. We therefore ranked $\hat{p}$ (covariate) models by $\triangle \mathrm{AIC}$ values (the difference between the Akaike's Information Criterion [AIC] value for each model and that of the model with the lowest AIC value). Only those with good empirical support (i.e. $\triangle \mathrm{AIC}<2$; Burnham \& Anderson 2002) were used in further analysis. Following the method of MacKenzie et al. (2006), we used additive models to investigate factors affecting $\hat{\psi}$ separately from those affecting $\hat{p}$. We then generated a set of models uniting the most influential combination of covariates for both $\hat{\psi}$ and $\hat{p}$.

We used AIC values for model selection (Burnham \& Anderson 2002). However, we did not use the small sample correction AICc because effective sample size could not be identified (MacKenzie et al. 2006). We checked goodness of fit of a global model containing all possible covariates using a chi-square test and 10000 boot- strap samples, and for over dispersion using the formula $\hat{c}=\chi^{2} /$ d.f. (MacKenzie et al.2006). We used model weight to determine relative evidence in favour of each model, and summed weights to determine which covariates were most influential on occupancy and detection probabilities (Burnham \& Anderson 2002; MacKenzie et al. 2006). We extracted maximum likelihood parameter estimates for $\hat{\psi}$ and $\hat{p}$ from the model with the lowest $\Delta \mathrm{AIC}$ value (most parsimonious) in the final set of models uniting the most influential covariates. If several models achieved similar weights, we used model averaging to derive parameter estimates from all models with weights $>0.01$ (Linkie et al. 2007). Where models contained site or surveyspecific occupancy and detection probabilities, we calculated overall probability as an average of the values, weighted by the number of sites or surveys in which they occurred (MacKenzie et al. 2006).

We assessed the effect that lures had on brown hyaena detection probability using $\hat{p}$ values and confidence intervals from the $\hat{\psi}$ (all site covariates), $\hat{p}$ (lures) model. Before extracting parameter values, we checked the $\hat{p}$ (lures) model for goodness of fit and compared it with the $\hat{\psi}$ (all site covariates), $\hat{p}$ (constant) model to ensure that there was sound empirical support for the $\hat{p}$ (lures) model.

\section{Modelling population size}

We found that we could individually identify brown hyaenas from the photographs, using leg stripes, facial scarring and ear notches as differentiators. We were therefore able to estimate abundance using mark-recapture analysis in the program CAPTURE (Rexstad \& Burnham 1991). We compiled detection histories for each individual from independent photographs (Karanth \& Nichols 2002). However, only one camera was used at each location and brown hyaena markings are bilaterally asymmetrical. We therefore restricted our analysis to photographs showing the left side of the animal as this gave us a larger sample size than right-sided photographs (O'Brien et al. 2003). Individual detection histories comprised six sampling occasions, each lasting 14 days.

\section{RESULTS}

\section{Captive trials}

The results of 40 food lure trials (see Fig. 1) showed that offal, followed by fish were the most successful food lures. Forty scent lure trials showed that eggs, followed by blood were the most successful scent lures. All four of these lures were 

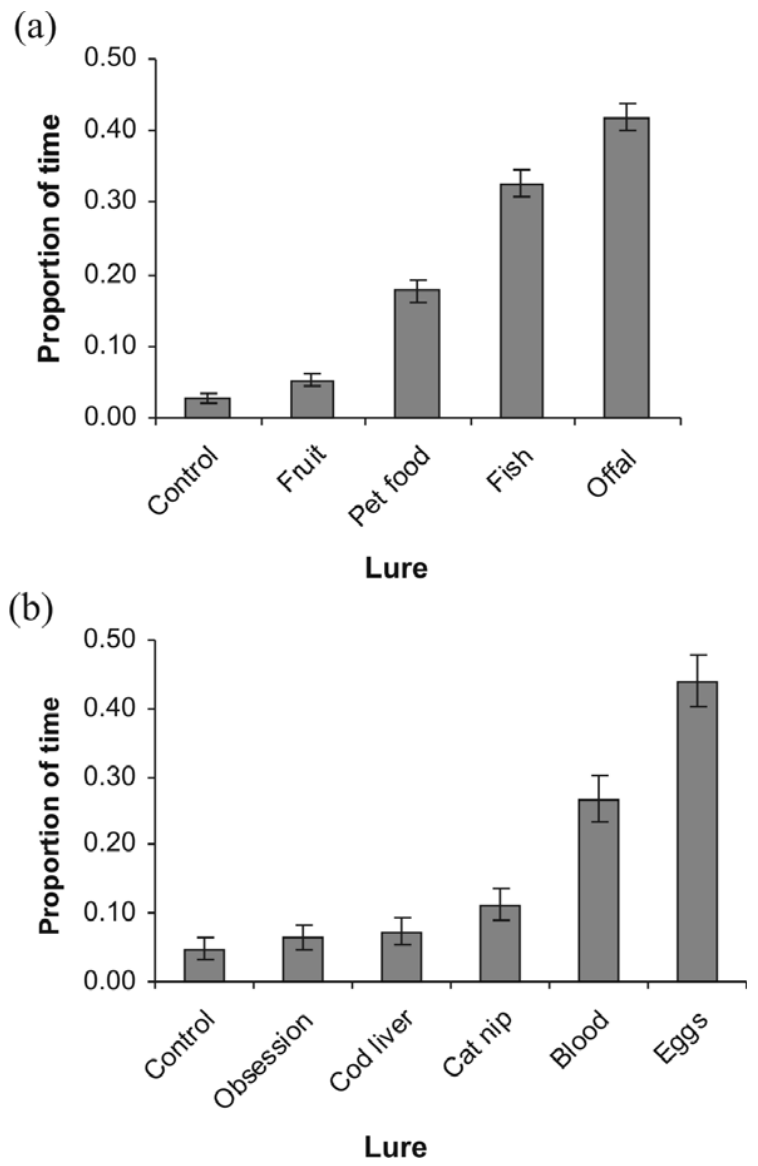

Fig. 1. Relative attractiveness of (a) food lures and (b) scent lures expressed as the proportion of time that eight captive carnivores spent investigating them. $n=40$ for each graph and $y$-axis error bars denote the $95 \%$ confidence interval calculated from the binomial distribution.

significantly more attractive than the control lure (test of two proportions, $P<0.001$ ) and were therefore selected for use in the camera trapping experiment.

\section{Camera trapping}

During 363 days of camera trapping, we obtained 264 independent photographs. Seventy two of these were of carnivore species (including brown hyaenas), 39 were small ungulates, other small mammals and birds, 75 were medium-sized ungulates and 22 were larger ungulates. The remaining photographs were of mega-herbivores, which were not analysed as they are unlikely to constitute a major part of brown hyaena diet (Mills \& Mills 1978; Owens \& Owens 1978; Mills 1987; Mills \& Hofer 1998; Maude 2005). We obtained 43 independent photographs of brown hyaenas, 27 of which were during baited periods. We were able to identify 10 individual brown hyaenas. Five of the six camera locations were used by hyaenas during unbaited, as well as baited weeks.

\section{Temporal independence}

There was no evidence of a temporal effect on brown hyaena encounter rates that would suggest development of trap prone or trap shy behaviour, confirming temporal independence of lure effects $\left(r^{2}=0, P=0.980\right.$, d.f. $\left.=4\right)$.

\section{$\psi$ and $p$ parameter estimates}

There was no evidence that the global model was a poor fit to the data (probability of test statistic $\geq$ observed from 10000 parametric bootstraps = 0.57). $\hat{c}$ was estimated at 0.0008 , indicating under-dispersal, but we did not apply a correction factor as there is presently no convention suggested for this procedure (MacKenzie et al. 2006). Model- 


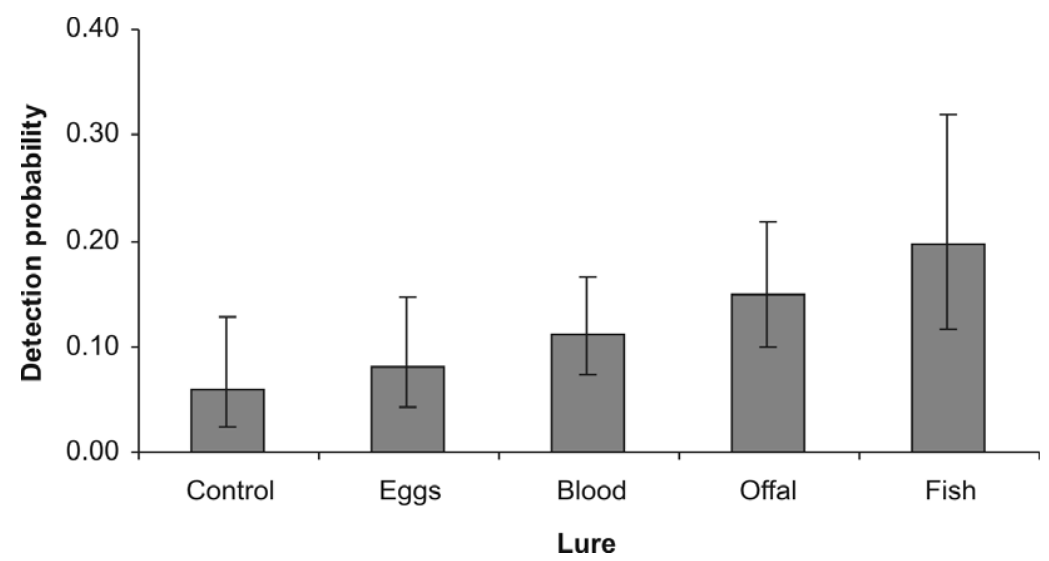

Fig. 2. Estimated detection probability of brown hyaenas associated with each lure. $n=6$ and $y$-axis bars denote the $95 \%$ confidence interval.

averaged brown hyaena $\hat{p}$ was 0.10 ( \pm 0.02 S.E.). Estimated PAU was 1.00 and we did not correct for false absences as hyaenas were detected at all locations.

\section{Population size}

Absolute abundance for brown hyaenas in the $36 \mathrm{~km}^{2}$ study area was estimated at 12 individuals $( \pm$ S.E. 2.37) using CAPTURE model $M($ th). Discriminant function model selection showed this model to be the best fit for the data (score $=1.00$ ), indicating that capture and recapture probabilities varied temporally and showed individual heterogeneity. The approximate $95 \%$ confidence interval for the estimate was 11 to 22 hyaenas.

We calculated the effectively sampled area by plotting a buffer strip around the polygon formed by the outer perimeter of the camera locations. We calculated the width of the buffer according to the equation $A=\pi r^{2}$, where $A$ is the estimated home range and $r$ is the buffer width (Soisalo \& Cavalcanti 2006). Preliminary telemetry data from an ongoing study suggests that brown hyaena home ranges in Pilanesberg are approximately $250 \mathrm{~km}^{2}$ (D. Scott \& R. Yarnell personal communication 2009), giving a buffer width of $8.9 \mathrm{~km}^{2}$ and an effectively sampled area of $424 \mathrm{~km}^{2}$. This produces a density estimate of 2.8 hyaenas/ $100 \mathrm{~km}^{2}$ with a $95 \%$ confidence interval of 2.6 to $5.2 / 100 \mathrm{~km}^{2}$ extrapolating to $n=15.6$ for the whole park, with a $95 \%$ confidence interval of 14.3 to 28.5 .

\section{Effect of covariates on $\hat{\psi}$ and $\hat{p}$}

The results offer no evidence that site-specific covariates influenced $\hat{\psi}$ as the constant $\hat{\psi}$ model ranked highest in the candidate model set.
However, there was strong evidence that habitat (summed weight $78 \%$ ) and lures (summed weight $73 \%$ ) influenced $\hat{p}$. Brown hyaenas were more likely to be detected by camera traps in areas of scrub or woodland rather than grassland and the influence of lures is discussed later in the results section. There was also moderate support for the premise that increased rainfall lowered $\hat{p}$ (summed weight $57 \%$ ) and weak support for similar temperature effects (summed weight $36 \%$ ).

\section{Effect of lures}

The detection probability of brown hyaenas was highest when the fish lure was deployed (see Fig. 2; $\hat{p}=0.2 \pm 0.05$ S.E.), followed by offal ( $\hat{p}=$ $0.15 \pm 0.03$ S.E.), blood ( $\hat{p}=0.11 \pm 0.02$ S.E.), eggs $(\hat{p}=0.08 \pm 0.03$ S.E. $)$ and the control lure $(\hat{p}=$ $0.06 \pm 0.03$ S.E.). None of the other lures differed significantly from the control, although the result for fish approached significance (based on the $95 \%$ confidence interval).

Brown hyaena encounter rates (see Fig. 3) were highest when the fish lure was used (0.33), followed in descending order by offal $(0.26)$, eggs $(0.22)$, blood (0.19) and the control lure (0.00). However, only the results for fish and offal were significantly higher than for the control lure (test of two proportions, $P \leq 0.001$ in both cases).

Brown hyaenas have a particularly acute sense of smell and can detect carrion from as far as $4 \mathrm{~km}$ downwind (Mills 1987). We were interested to know if the outcome would be similar for carnivores with lesser olfactory acuity. To determine this, we pooled data for jackals, honey badgers (Mellivora capensis), servals, leopards (Panthera pardus), African wild cats (Felis silvestris) and lions 


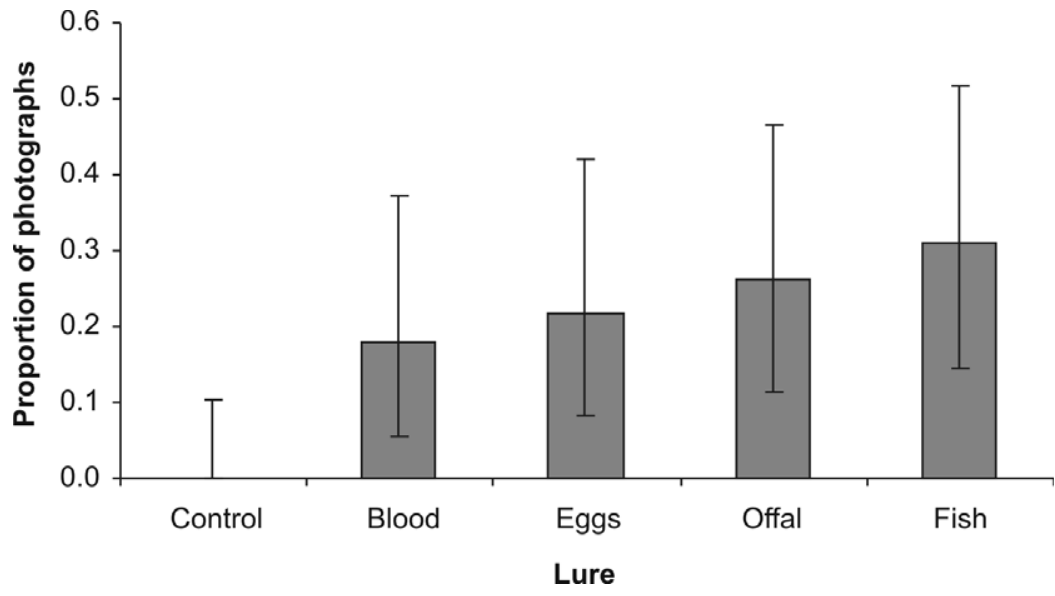

Fig. 3. Proportion of brown hyaena photographs associated with each lure, standardized by trapping effort. $n=27$ and $y$-axis bars denote the $95 \%$ confidence interval calculated from the binomial distribution.

(Panthera leo) as sample sizes were insufficient for analysis of individual species. We analysed the results in the same way as for brown hyaenas. The results for the multi-species data set showed that detection probability was significantly higher (non-overlapping confidence intervals) when fish was used ( $\hat{p}=0.16 \pm 0.05$ S.E.), compared with the control lure $(\hat{p}=0.02 \pm 0.02$ S.E. $)$. All of the other lures increased $\hat{p}$, but not significantly.

\section{DISCUSSION}

\section{Population size and density}

Our density estimate is higher than estimates from the southern Kalahari (approximately $1.8 / 100 \mathrm{~km}^{2}$; Mills \& Mills 1982), and the Makgadikgadi area of Botswana (up to $2.0 / 100 \mathrm{~km}^{2}$ extrapolated from the estimated territory size of five collared individuals; Maude 2005). This may indicate that food items in Pilanesberg are less dispersed or of higher quality (Mills \& Mills 1982), or that apex predators are facilitating brown hyaenas as in Mills (1978). Temporal variations in capture probabilities most likely resulted from the different combinations of lures corresponding to each sampling occasion. Individual heterogeneity in capture probabilities probably reflects brown hyaena territoriality, which creates unequal access to the camera traps (Karanth \& Nichols 2002).

\section{Covariates}

The results showed that using lures increased brown hyaena detection, and camera traps should be placed in scrub or woodland areas where brown hyaenas often rest during the day (Mills \& Hofer 1998). Rainfall and temperature were influential $\hat{p}$ covariates, but these factors received only moderate to weak support. It is possible that hyaena activity and therefore detection probability may have been lower during rainfall (Otis et al. 1978), and Owens \& Owens (1978) found brown hyaenas to be particularly heat sensitive. However, temperature effects might also be explained by impaired camera trap function. Infrared sensors are able to detect animal body heat because it differs from ambient temperatures, but on hot days the sensors may fail to detect animals (Karanth \& Nichols 2002) or take too long to trigger the camera (M. Thorn, pers. obs.). Brown hyaenas are largely independent of water (Mills \& Mills 1978; Owens \& Owens 1978; Mills \& Hofer 1998), which probably explains why it did not affect detection. Brown hyaena prey availability is influenced by live prey abundance and the carcasses left by other predators (Mills \& Mills 1978). Prey selection is largely secondary as brown hyaenas obtain most of their food by scavenging (Mills \& Mills 1978; Owens \& Owens 1978; Mills 1987; Mills \& Hofer 1998; Maude 2005). This indirect link between prey abundance and selection may explain why we did not find prey abundance to be an influential covariate. However, it is also possible that our encounter rates imperfectly reflected prey abundance and if so, this might also explain why the affect of prey abundance did not appear to be significant. Brown hyaenas are reported to favour mountainous bushveld areas (Mills \& Hofer 1998), but our study found no evidence of an elevation preference. Mills \& Hofer (1998) also suggest that the species is tolerant of anthropogenic disturbance, surviving near urban areas. Our results show that 
neither distance from disturbance sites nor distance from roads were influential covariates. Site-specific covariates did not influence $\hat{\psi}$, which is not surprising as the survey area was chosen for its homogenous habitat.

\section{Lures}

Fish, offal, fermented eggs and blood were effective lures for captive carnivores in general. However, although 80 trials were completed, only eight individuals were tested, preventing generalization of the results to species level. Testing a larger number of individuals from each species would probably require access to several animal collections but might reveal species-specific preferences that could not be inferred from this study. Such data would be useful not only for camera trapping but also for wider use including vaccine delivery, pest control, enrichment or breeding programmes for captive animals, bait marking and live trapping studies. Using camera traps in lure-related studies may allow non-invasive observation of wild animals, which is particularly beneficial if the presence of observers might bias the results (Cutler \& Swann 1999; Wilson \& Delahay 2001).

The camera trapping experiment showed that using the fish lure produced a $100 \%$ increase in brown hyaena $\hat{p}$, and using fish or offal significantly increased encounter rates for several other carnivore species as well as brown hyaenas. These results demonstrate that lures can considerably improve detection of African carnivores during camera trapping. However, there are numerous variables that impact lure efficacy. For example, food lures may freeze during cold weather, reducing their olfactory stimulus. They also require more frequent replacement than scent lures, which may be logistically problematic. Such limitations and their solutions are specific to the circumstances of each investigation, but our results demonstrate that lures should be used if survey constraints permit.

\section{Implications for survey design}

MacKenzie \& Royle (2005) calculated the optimum number of replicates per site, and the number of sites that should be surveyed based on the anticipated occupancy and detection probability of the focal species. Applying our model-averaged parameter estimates to their results (standard design), a minimum of 34 sampling occasions would be required to survey brown hyaena occu- pancy in similar high-density bushveld sites. However, using the fish lure increased $\hat{p}$, reducing the required number of occasions to just 16 . This is beneficial as shorter survey duration may alleviate time, manpower, logistical or cost constraints. With or without lures, 13 camera sites would be needed to achieve an estimate of $\hat{\psi}$ with S.E. of 0.05 in high-density bushveld habitat, using the same survey design and trap spacing as in our study.

\section{Management implications}

The purpose of our study was to evaluate the efficacy of camera trapping for estimating brown hyaena occupancy and collecting data that will contribute to accurate assessment of the species conservation status. We found that camera trapping is an effective method for measuring brown hyaena occupancy and that capture-recapture analysis is also possible, as we were able to unambiguously identify individuals from photographs. This option is attractive for conservation-dependent species because key parameters like survival and recruitment can be calculated from long-term data sets (Otis et al. 1978; Karanth \& Nichols 2002). Ideally, this requires two camera traps at each camera site so that both sides of the individual are photographed simultaneously (Karanth \& Nichols 2002). If camera numbers are limited, our results and those of O'Brien et al. (2003) show that adequate sample sizes can be achieved using single camera traps and differentiating individuals using only those photographs that show the same side of the body. However, logistical constraints would make capture-recapture camera trapping impractical at landscape scale so this option is best suited to intensive, small-scale studies.

Although we focused on a relatively small area, occupancy estimation at large spatial scales could be achieved using camera trapping. This would require selection of independent survey sites by means of a probabilistic sampling scheme, a survey duration that minimizes the likelihood of changes in occupancy, and covariate modelling of all sources of heterogeneity in $\psi$ and $p$ (Mac Kenzie et al. 2006). The resulting estimates of occupancy or population size would refer to the 'super-population' of brown hyaenas using each survey site and the surrounding area (MacKenzie et al. 2006). Site estimates could be then generalized to the wider survey area and used to monitor populations at landscape scale. However, our results suggest that Pilanesberg is a high-density site and our methods may perform differently in 
low-density areas of the species range. Realistically, further estimates of $\Psi$ and $p$ will be required from a range of representative habitats and population densities to construct landscape-scale protocols and determine the number of survey sites needed to detect meaningful changes in occupancy.

\section{ACKNOWLEDGEMENTS}

We are indebted to the North West Parks and Tourism Board, particularly Steven Dell, for allowing us access to Pilanesberg National Park. We thank Marcel Tournier and San Mare Pretorius at Predator World for letting us carry out the lure trials, and Steve Uzzell for the computer equipment he provided. We thank Steve Waite, Richard Yarnell and two anonymous reviewers for comments on the manuscript. We thank the University of Brighton, U.K., and the Leverhulme Trust U.K. for funding and Project Phiri in association with Earthwatch Institute for support. Finally, we would like to thank Ullas K. Karanth for inspiring this occupancybased approach.

\section{REFERENCES}

ANDELT, W.F. \& WOOLEY, T.P. 1996. Responses of urban mammals to odor attractants and a baitdispensing device. Wildlife Soc. B. 24(1): 111-118.

BRADSHAW, J.W.S., HEALEY, L.M., THORNE, C.J., MACDONALD, D.W. \& ARDEN-CLARK, C. 2000. Differences in food preferences between individuals and populations of domestic cats Felis silvestris catus. Appl. Anim. Behav. Sci. 68: 257-268.

BURNHAM, K.P. \& ANDERSON, D.R. 2002. Model selection and multimodel inference: a practical information-theoretic approach, second edition, SpringerVerlag, New York.

CUTLER, T.L. \& SWANN, D.E. 1999. Using remote photography in wildlife ecology: a review. Wildlife Soc. B. 27(3): 571-581.

DE VILLIERS, B. \& MANGOLD, S. 2002. Chapter 2: The biophysical environment. In: D. WALMSLEY, J. WALMSLEY, S. MANGOLD \& M. KALULE-SABITI, North West Province state of the environment report. Directorate of Environment and Conservation Management, North West Department of Agriculture, Conservation and Environment, South Africa.

GROBLER, J.H. 1981. Feeding behaviour of the caracal Felis caracal Schreber 1776 in the Mountain Zebra National Park. S. Afr. J. Zool. 16: 259-262.

HINES, J.E. 2006. PRESENCE 2 - Software to estimate patch occupancy and related parameters. USGSPWRC; http://www.mbr-pwrc.usgs.gov/software/ presence.html

HOWARD, M.E., ZUERCHER, G.L., GIPSON, P.S. \& LIVINGSTON, T.R. 2002. Efficacy of feces as an attractant for mammalian carnivores. Southwest. Nat. 47(3): 348-352.

KARANTH, K.U. \& NICHOLS, J.D. (Eds) 2002. Monitor- ing tigers and their prey: a manual for researchers, managers and conservationists in tropical Asia. Centre for Wildlife Studies, Bangalore.

KAUFFMAN, M.J., SANJAYAN, M., LOWENSTEIN, J., NELSON, A., JEO, R.M. \& CROOKS, K.R. 2007. Remote camera-trap methods and analyses reveal impacts of rangeland management on Namibian carnivore communities. Oryx 41(1): 70-78.

LINKIE, M., DINATA, Y., NUGROHOB, A. \& HAIDIRC, I.A. 2007. Estimating occupancy of a data deficient mammalian species living in tropical rainforests: Sun bears in the Kerinci-Seblat region, Sumatra. Biol. Conserv. 137: 20-27.

MACE, R.D., MINTA, S.C., MANLEY, T.L. \& AUNE, K.A. 1994. Estimating grizzly bear population size using camera sightings. Wildlife Soc. B. 22: 74-83.

MACKENZIE, D.I. \& ROYLE, J.A. 2005. Designing occupancy studies: general advice and allocating survey effort. Ecol. Appl. 42: 1105-1114.

MACKENZIE, D.I., NICHOLS, J.D., SUTTON, N., KAWANISHI, K. \& BAILEY, L.L. 2005. Improving inferences in population studies of rare species that are detected imperfectly. Ecology 86(5): 1101-1113.

MACKENZIE, D.I., NICHOLS, J.D., ROYLE, J.A., POLLOCK, K., BAILEY, L. \& HINES, J.E. 2006. Occupancy estimation and modelling - inferring patterns and dynamics of species occurrence. Elsevier Publishing, London.

MARNEWICK, K.A., BOTHMA, J. DU P. \& VERDOORN, G.H. 2006. Using camera-trapping to investigate the use of a tree as a scent-marking post by cheetahs in the Thabazimbi district. S. Afr. J. Wildl. Res. 36(2): 139-145.

MARNEWICK K., FUNSTON P. J. \& KARANTH K.U. 2008. Evaluating camera trapping as a method for estimating cheetah density - a pilot study. S. Afr. J. Wildl. Res. 38(1): 59-65.

MAUDE, G. 2005. The comparative ecology of the brown hyaena (Hyaena brunnea) in Makgadikgadi National Park and a neighbouring community cattle area in Botswana. M.Sc. thesis, University of Pretoria.

McDANIEL, G.W., McKELVEY, K.S., SQUIRES, J.R. \& RUGGIERO, L.F. 2000. Efficacy of lures and hair snares to detect lynx. Wildlife Soc. B.28(1):119-123.

MICKLEBURGH, S. \& FISHER, M. 2003. Briefly: Calvin Klein perfume may help attract Asiatic cheetahs. Oryx 37(4): 394.

MILLS, M.G.L. 1978. Foraging behaviour of the brown hyaena (Hyaena brunnea Thunberg, (1820)) in the southern Kalahari. Z. Tierpsychol. 48: 113-141.

MILLS, M.G.L. 1987. Behavioural adaptations of brown and spotted hyaenas in the southern Kalahari. S. Afr. J. Sci. 83: 595-598.

MILLS, M.G.L. \& HOFER, H. (Eds) 1998. Hyaenas. Status survey and conservation action plan. IUCN/ SSC Hyaena Specialist Group. IUCN, Gland and Cambridge.

MILLS, M.G.L. \& MILLS, M.E.J. 1978. The diet of the brown hyaena Hyaena brunnea in the southern Kalahari. Koedoe 21: 125-149.

MILLS, M.G.L. \& MILLS, M.E.J. 1982. Factors affecting the movement patterns of brown hyaenas, Hyaena brunnea, in the Southern Kalahari. S. Afr. J. Wildl. Res. 12: 111-117. 
MORUZZI, T.L., FULLER, T.K., DEGRAAF, R.M., BROOKS, R.T. \& LI, W. 2002. Assessing remotely triggered cameras for surveying carnivore distribution. Wildlife Soc. B. 30(2): 380-386.

NOWELL, K. \& JACKSON, P. (Eds) 1996. Wild cats. Status survey and conservation action plan. IUCN/ SSC Cat Specialist Group. IUCN, Gland.

NOYCE, K.V., GARSHELIS, D.L. \& COY, P.L. 2001. Differential vulnerability of black bears to trap and camera sampling and resulting biases in markrecapture estimates. Ursus 12: 211-225.

O'BRIEN, T.G., KINNIARD, M.F. \& WIBISONO, H.T. 2003. Crouching tigers, hidden prey: Sumatran tiger and prey populations in a tropical forest landscape. Anim. Conserv. 6: 131-139.

OTIS, D.L., BURNHAM, K.P., WHITE, G.C. \& ANDERSON, D.R. 1978. Statistical inference from capture data on closed animal populations. Wildlife Monogr. 62: 1-135.

OWENS, M.J. \& OWENS, D.D. 1978. Feeding ecology and its influence on social organization in brown hyaenas (Hyaena brunnea, Thunberg) of the central Kalahari Desert. E. Afr. Wildl. J. 16: 113-135.

REXSTAD, E. \& BURNHAM, K.P. 1991. User's guide for interactive program CAPTURE. Colorado State University, Fort Collins.

ROWE-ROWE, D.T. 1982. Black backed jackal diet in relation to food availability in the Natal Drakensberg. Natal Parks Board, Pietermaritzburg.

ROYLE, J.A. \& NICHOLS, J.D. 2003. Estimating abundance from repeated presence-absence data or point counts. Ecology 84: 777-790.

SKINNER, J.D., VAN AARDE, R.J. \& GOSS, R.A. 1995. Space and resource use by brown hyaenas Hyaena brunnea in the Namib Desert.
J. Zool. Lond. 237: 123-131.

SMITHERS, R.H.N. 1978. The serval Felis serval Schreber, 1776. S. Afr. J. Wildl. Res. 8: 29-37.

KARANTH, K.U. \& NICHOLS, J.D. 1998. Estimation of tiger densities in India using photographic captures and recaptures. Ecology 79: 2852-2862.

KARANTH, K.U. \& NICHOLS, J.D. (Eds) 2002. Monitoring tigers and their prey: a manual for researchers, managers and conservationists in tropical Asia. Centre for Wildlife Studies, Bangalore.

SOISALO, M.K. \& CAVALCANTI, S.M.C. 2006. Estimating the density of a jaguar population in the Brazilian Pantanal using camera-traps and capture- recapture sampling in combination with GPS radio-telemetry. Biol. Conserv. 129: 487-496.

WIESEL, I., MAUDE, G., SCOTT, D. \& MILLS, G. 2008. Hyaena brunnea. In: 2008 IUCN Red List of Threatened Species; http://www.iucnredlist.org, Gland.

WILSON, G.J. \& DELAHAY, R.J. 2001. A review of methods to estimate the abundance of terrestrial carnivores using field signs and observation. Wildlife Res. 28: 151-164.

ZIELINSKI, W.J. 1995. Track plates. In: W.J. Zielinski \& T.E. Kucera (Eds), American marten, fisher, lynx, and wolverine: survey methods for their detection. General Technical Report PSW-GTR-157, Pacific Southwest Research Station. U.S. Department of Agriculture Forest Service, Albany.

ZIELINSKI, W.J. 1997. Monitoring mesocarnivore population status In: J. Harris \& C. Ogan (Eds), Mesocarnivores of northern California: Biology, management, and survey techniques. Humboldt State University, The Wildlife Society, California North Coast Chapter, Arcata. 